\title{
Game Renascença na disciplina de Literatura Portuguesa no curso superior de Letras
}

\author{
Romero Araújo de Medeiros ${ }^{1}$, Raniella Lima ${ }^{2}$, Denise Silva ${ }^{2}$, Luis Paulo Leopoldo Mercado ${ }^{2}$ \\ ${ }^{1}$ Instituto Federal de Pernambuco - Campus Garanhuns - IFPE (PE) \\ CEP 55297-130 - Garanhuns - PE - Brasil \\ ${ }^{2}$ Centro de Educação - Universidade Federal de Alagoas - UFAL (AL) \\ CEP 57072-970 - Maceió - AL - Brasil
}

romero.medeiros@garanhuns.ifpe.edu.br, raniella.lima@reitoria.ufal.br, denises1102@gmail.com, luispaulomercadolgmail.com

\begin{abstract}
Resumo. Esta proposta é baseada na aprendizagem com jogos digitais, buscando acrescentar ao ensino superior uma metodologia ativa, em que o aluno também atue no processo de ensino-aprendizagem. Nessa perspectiva é indispensável o uso de TICS como recurso para proporcionar aulas mais dinâmicas e interativas. O objetivo dessa prática com jogos é que o aluno possa, além de aprender o conteúdo específico da aula, desenvolver competências e habilidades úteis no ambiente extra-acadêmico. O foco é o envolvimento e o prazer que o aluno sente ao jogar, aprendendo de forma oblíqua, sem se preocupar necessariamente com um conteúdo, destacando o interesse dos aluno, empolgação e também aprendizagem em relação ao assunto trabalhado.
\end{abstract}

\section{Cenário de Uso}

Neste estudo experimentamos a estratégia Aprendizagem com Jogos, elaborada para uma aula de Literatura do Curso de Letras, discorrendo sobre todo o processo desde o levantamento do conteúdo para a criação de um jogo específico para a aula, até a aplicação e avaliação do jogo por parte dos alunos.

\section{Desenvolvimento}

A construção deste game justifica-se pela necessidade de um conteúdo específico de acordo com o plano de aula elaborado. Inicialmente, a equipe pensou na arquitetura e conteúdo do jogo, em seguida deu-se o processo de construção.

A fim de implementar o modelo, foi desenvolvido um protótipo com as ferramentas de construção de games (GSM - Game Creation Systems), RPG Maker VX Ace e Game Maker Studio. Os RPG Makers são ferramentas de criação de Role Playing games eletrônicos, com características simples como a linearidade de criação de histórias e um único jogador controlando os eventos, havendo pouca variedade deste tipo de aplicação no mercado de jogos eletrônicos (GIRAFFA E BITTENCOURT, 2003a). Para consoles, especificamente Playstation e Playstation 2, existe o Maker da Agetec. Para o sistema operacional Windows, o mais conhecido Maker é o desenvolvido pela empresa japonesa EnterBrain (GIRAFFA E BITTENCOURT, 2003b). Esta empresa criou várias versões deste produto, como o RPG Maker 95, 2000, 2003, XP e VX. Alguns produtos foram lançados apenas para o Japão, como o RPG Tsukuru for Móbile, para criação de jogos em celular. Pela facilidade e rapidez de implementação optamos por desenvolver o protótipo com a versão VX Ace da EnterBrain.

Para jogos eletrônicos o uso de linguagens de scripts é o mais indicado, evitando o processo de compilação, dando agilidade ao processo de criação. Entre as linguagens mais usadas em jogos 
estão: Lua, Ruby e Python (VALENTE 2005). O RPG Maker faz uso da linguagem de script Ruby.

Ruby é uma linguagem de script desenvolvida pelo japonês Yukihiro Matsumoto e caracteriza-se pela simplicidade e fácil integração e sua aprendizagem rápida, possuindo um bom conjunto de bibliotecas com recursos diversos, e com seu processo de instalação bastante claro, indicando seu uso também em projetos de criação de interface gráfica como o FXRuby (DIAS 2005). Todas estas características influenciam o uso desta linguagem não só para jogos, mas também para uma vasta gama de aplicações.

O Game Maker Studio é uma ferramenta para criação de games com portabilidade para várias plataformas, podendo o jogo desenvolvido ser adaptado para vários sistemas operacionais como Windows, Linux, Android e IOS, e com possibilidade de conversão para HTML5. Criado originalmente pelo professor de computação holandês Mark Overmars, é produzido pela empresa Yoyo Games. Utiliza uma linguagem própria chamada GML (Game Maker Language), mas podem ser usados eventos e ações para a criação dos jogos.

\section{Apresentação do software}

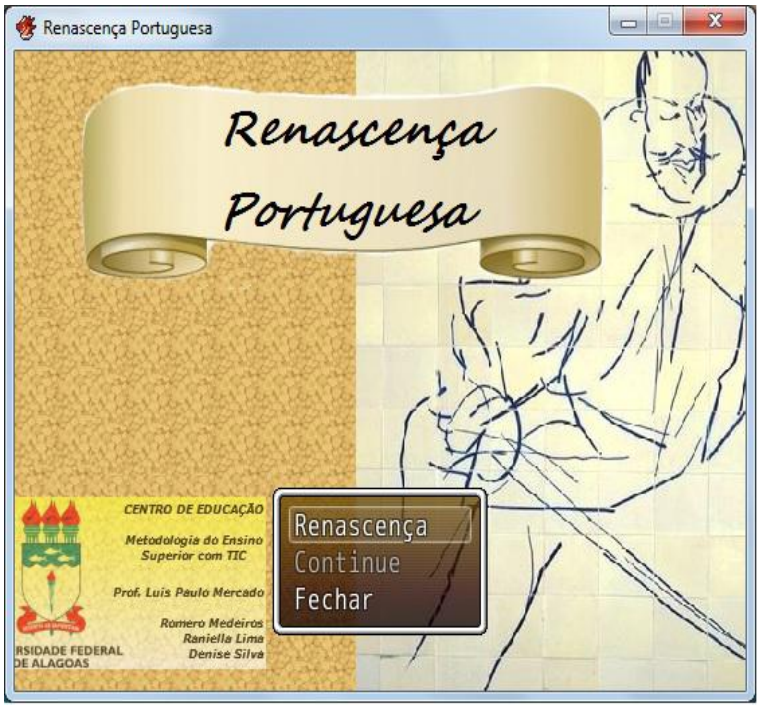

Figura 1: tela de abertura do RPG.

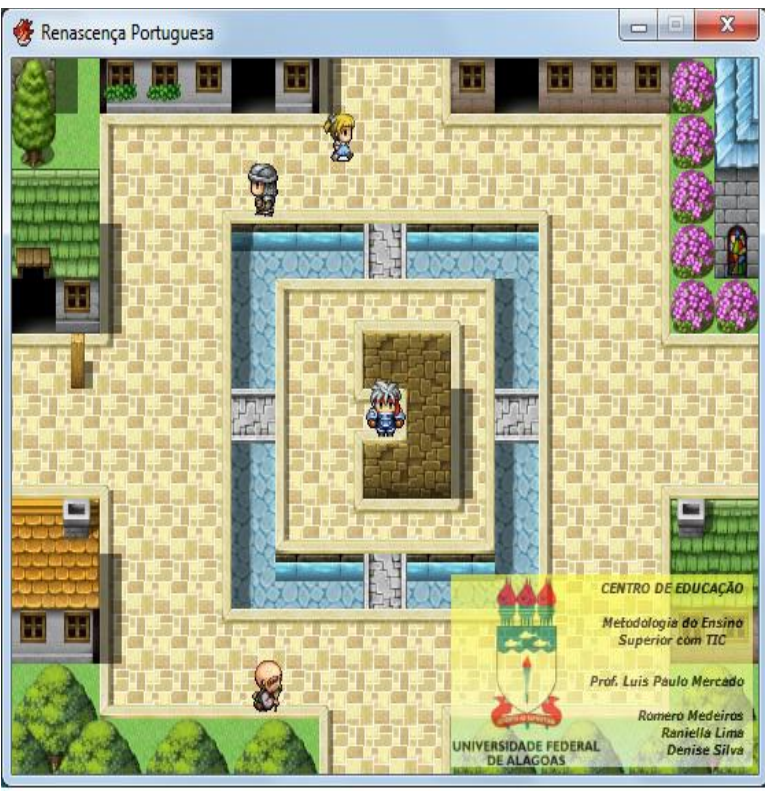

Figura 3: mapa inicial do RPG.

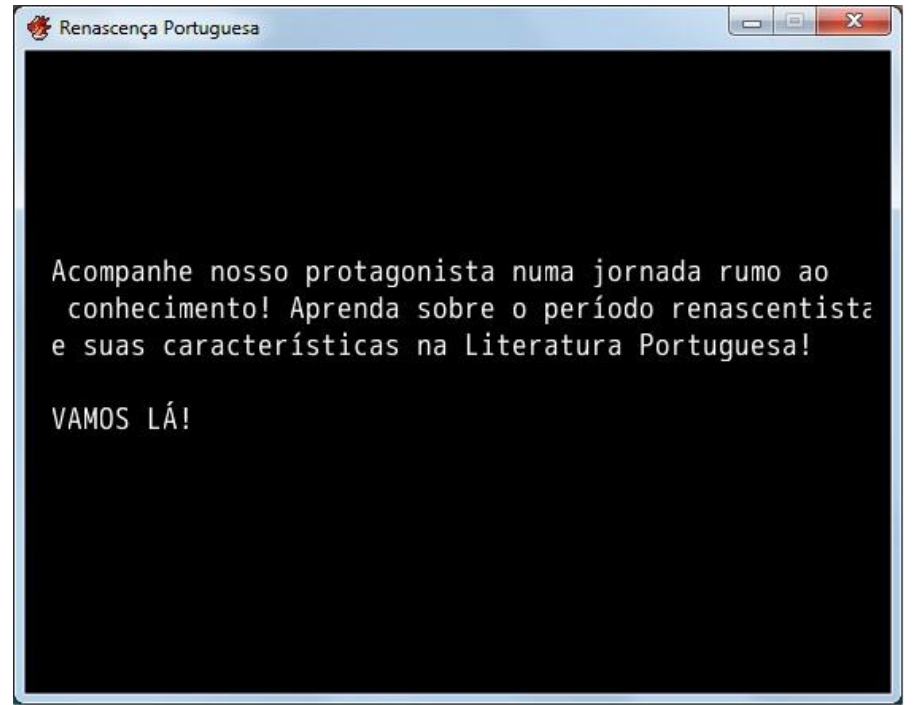

Figura 2: introdução ao RPG

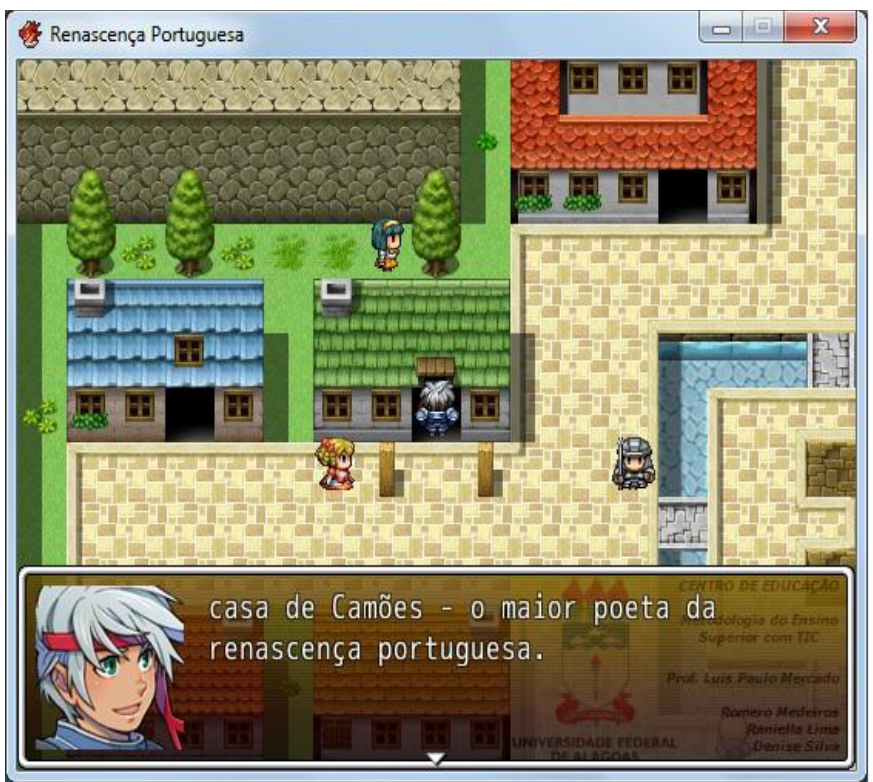

Figura 4: ponto de entrada do $2^{\circ}$ mapa. 


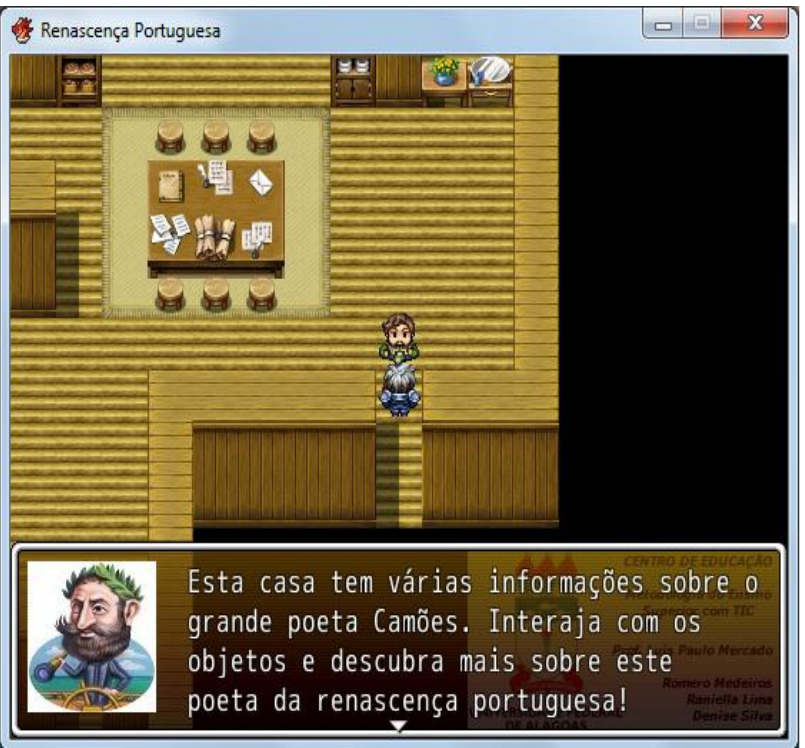

Figura 5: interação com personagem não jogador.

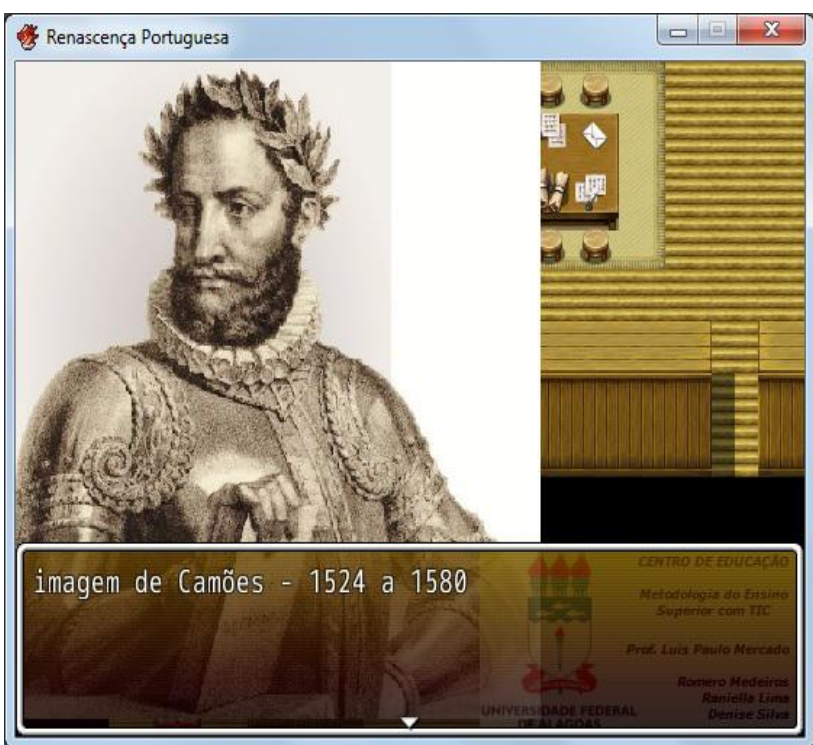

Figura 7: interação com objetos - exemplo 2.

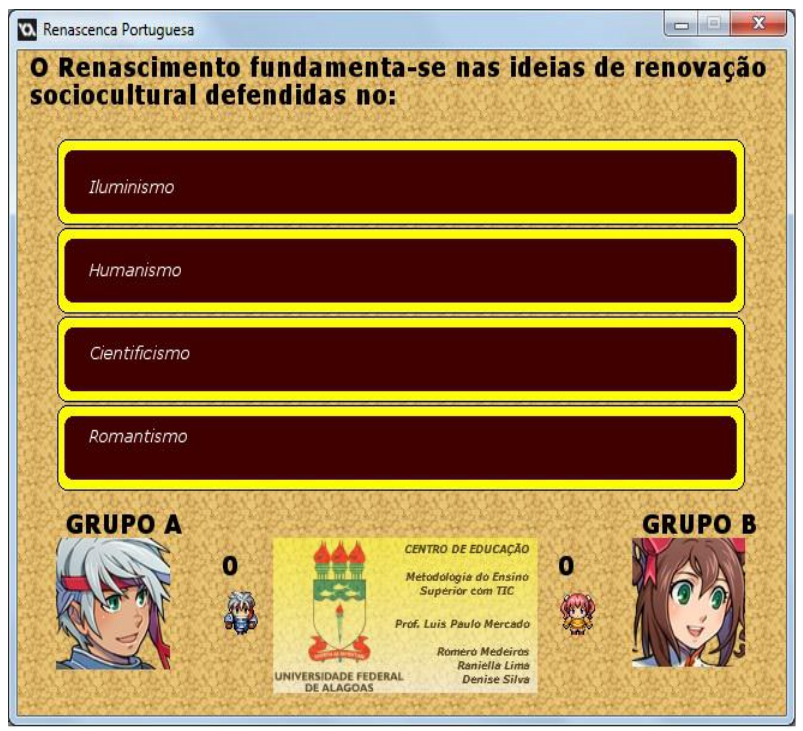

Figura 9: tela com questão sobre Renascimento.

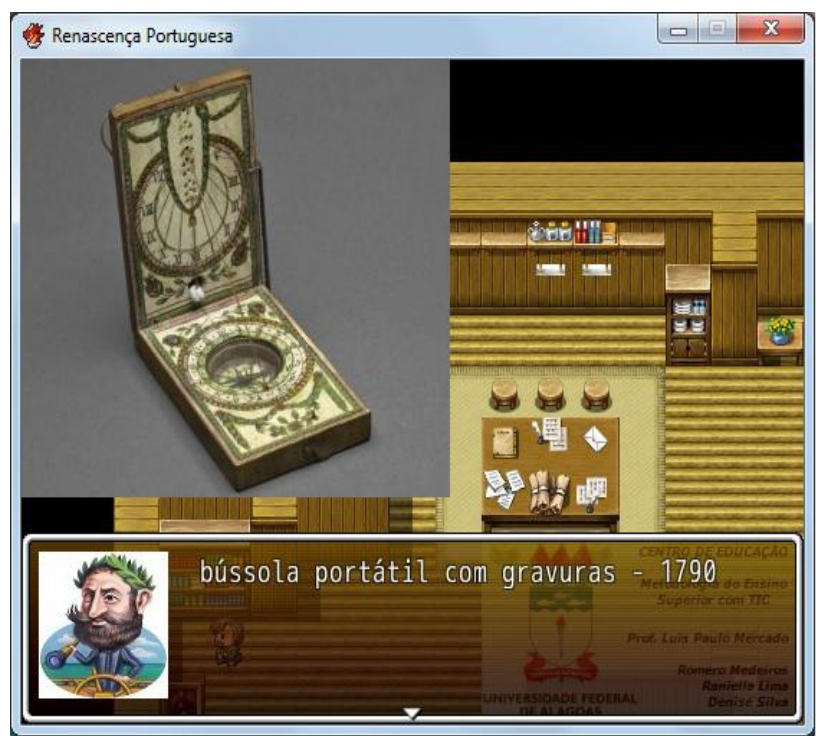

Figura 6: interação com objetos - exemplo 1.

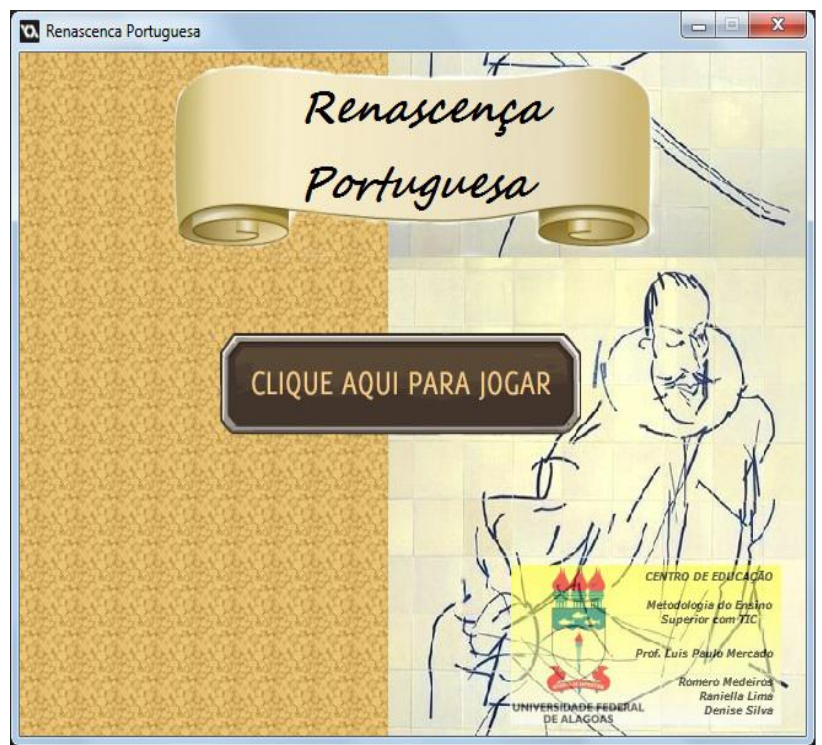

Figura 8: tela de abertura do QUIZ.

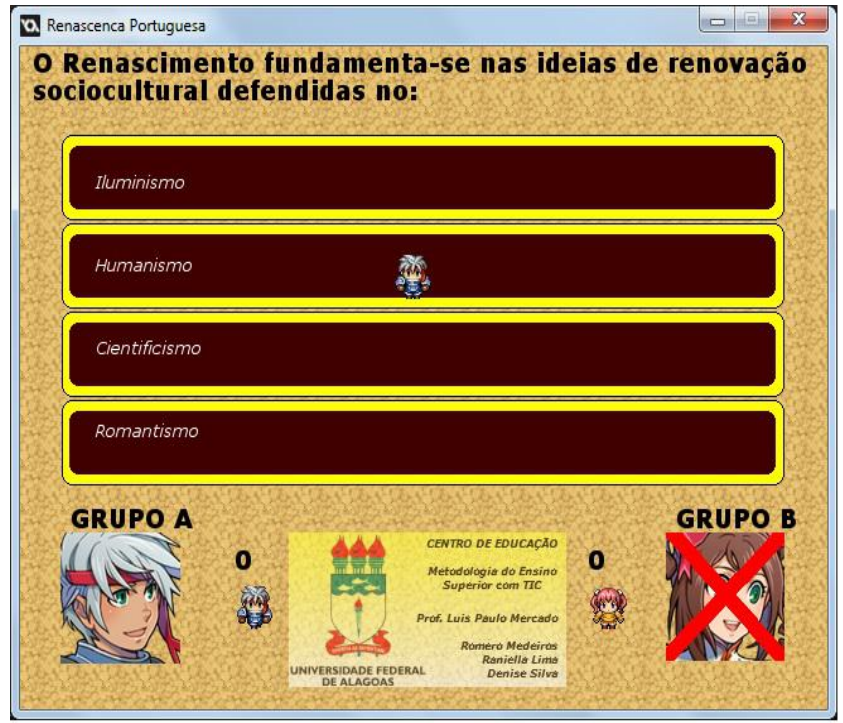

Figura 10: Grupo A aciona primeiro o QUIZ. 


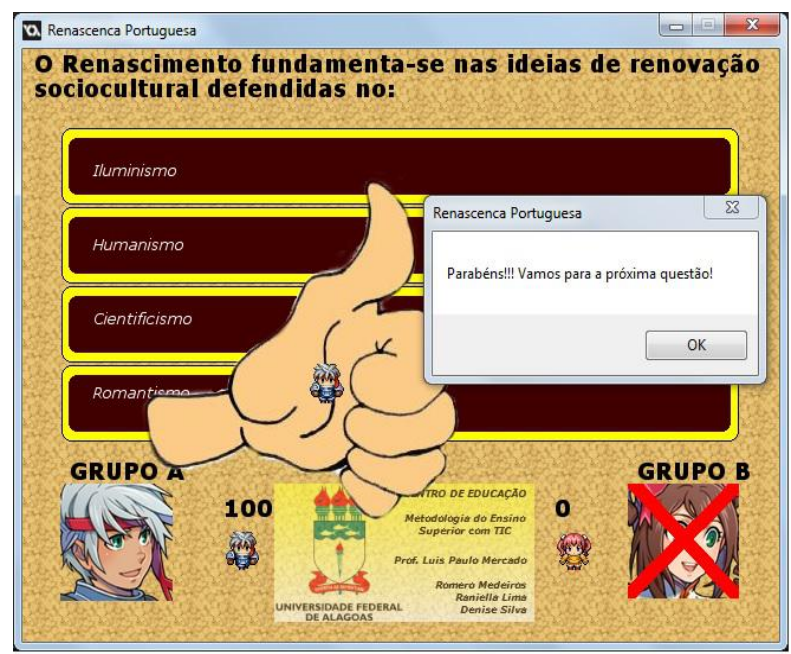

Figura 11: grupo A acerta questão.

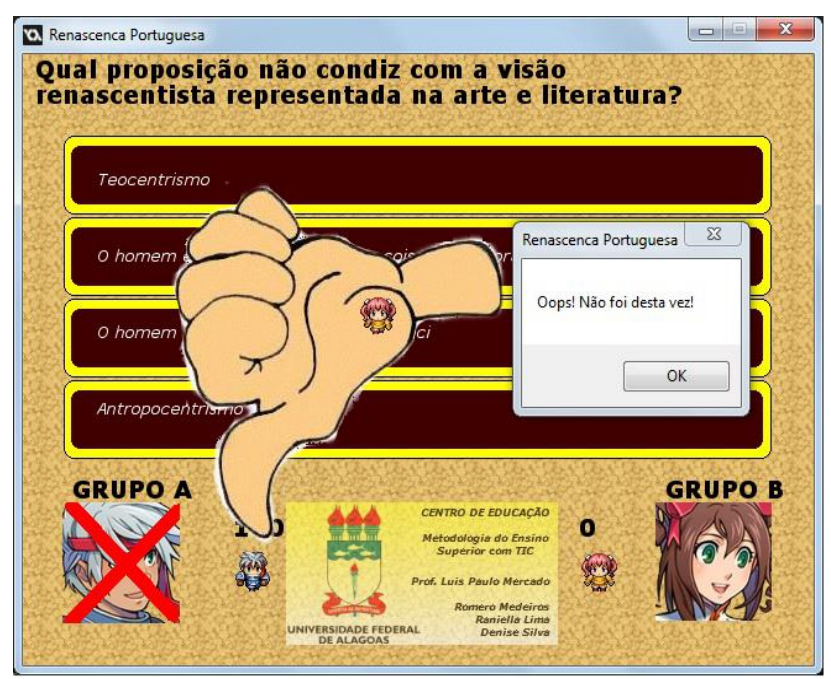

Figura 13: grupo B erra a questão.

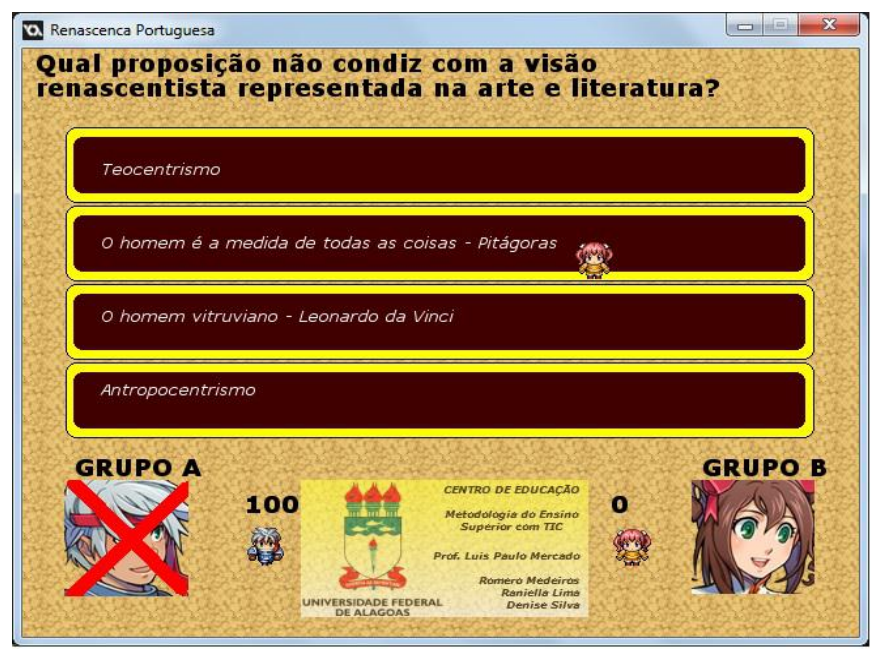

Figura 12: Grupo B aciona o QUIZ.

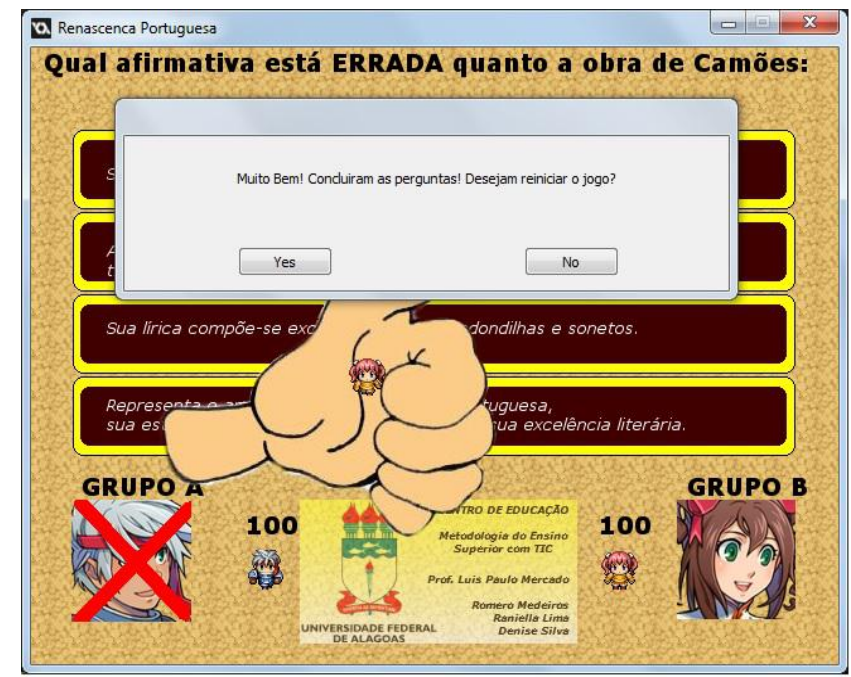

Figura 14: finalização do QUIZ.

O objetivo do protótipo é, além de mostrar a funcionalidade do modelo proposto, salientar a aprendizagem da Literatura em um curso superior de Letras. A ferramenta poderá servir de apoio pedagógico a professores do ensino superior por meio da forma lúdica.

$\mathrm{O}$ jogo foi dividido em duas etapas. Na primeira, um Role Playing Game (RPG), os alunos jogam assumindo personagens virtuais que interagem com textos e imagens referentes à Literatura Renascentista de Portugal, conhecendo o contexto histórico, as características, o principal autor e obra. Nesta etapa, a abertura do jogo faz referência ao contexto da Renascença com a imagem de Camões (Figura 1), apresentando em seguida uma pequena síntese (Figura 2) para logo depois apresentar o personagem lançado no mapa principal do jogo (Figura 3). A partir daí ele é guiado até o ponto da "casa de Camões"(Figura 4), espaço onde ele irá interagir com um personagem não jogador (PNJ) (Figura 5) que irá orientá-lo em sua exploração. À medida que o personagem interage com os objetos renascentistas (figuras 6 e 7) e PNJ que estão no recinto, ele ganha pontos em sua jornada, aumentando a imersão do jogador na história e por consequência nos fatos históricos.

$\mathrm{Na}$ segunda etapa, a turma é dividida em 2 equipes para competir em um quiz, em uma disputa onde cada representante de cada grupo deve apertar primeiro a tecla para ter direito a 
responder a pergunta. Assim como na tela inicial do RPG, o quiz tem Camões (Figura 8) como imagem de abertura. A tela seguinte vai direto à questão, onde mostra a pergunta e suas possíveis respostas (Figura 9), que só poderão ser escolhidas após a disputa entre os representantes dos grupos (aquele que apertar primeiro a tecla "A" - representante do grupo A - ou tecla "B" representante do grupo B). Na Figura 10 percebemos que o grupo vencedor foi o "A", indicando um " $x$ " na imagem do adversário, e fazendo com que a seta do mouse passe a ser identificada também com a imagem do personagem que representa o grupo. Se o representante escolher a resposta correta, ele ganha pontos para sua equipe (figura 11). As Figuras 12 e 13 mostram quando um grupo não acerta uma questão, ficando este sem ganhar sua pontuação. Ao acabarem as perguntas é questionado se deseja reiniciar o jogo, para reforçar os conhecimentos sobre o assunto (Figura 14). Tanto no RPG quanto no quiz, o aluno acumula pontuação que poderá servir como parte da avaliação.

Foi distribuído um questionário para alunos opinarem sobre o jogo ao final de uma aula sobre o assunto, tecendo críticas e/ou elogios necessários para o aperfeiçoamento do jogo. Todos concordaram que o jogo foi claro, tecnicamente adequado, e que tinha chamado a sua atenção, um indicativo positivo deste método de aprendizagem. A maioria diz ter experiência razoável com microcomputadores, mas afirmam ter pouca ou nenhuma experiência com jogos eletrônicos. Entretanto, metade achou fácil de jogar, e a outra metade encontrou alguma dificuldade. Os pontos positivos citados foram diversão, o processo lúdico, motivação, competitividade (quiz), dinâmica, proposta criativa, facilidade de uso, estrutura técnica, jogabilidade, abordagem do conteúdo, a possibilidade de memorização, a interação, a imersão, autoinstrução, design atrativo e conteúdo relevante. Já os pontos negativos foram a necessidade de introdução mais detalhada, um guia rápido, conteúdo pedagógico limitado, acesso ao jogo, explicitar como ganhar mais pontos, padronizar a estética do jogo e eventual lentidão do personagem. Foi também sugerido a criação de uma história introdutória para o personagem, ampliar os mapas do jogo, usar a tela cheia e um mini tutorial.

\section{Considerações finais}

A avaliação geral dos protótipos foi positiva, haja vista que o objetivo de ser um elemento lúdico, dinâmico de aprendizagem foi atingido, extrapolar os limites da sala de aula, oportunizando aos alunos o desenvolvimento de competências e habilidades relativas aos jogos, tais como: a concentração, raciocínio rápido e empolgação. Esperamos evoluir o projeto adicionando mais conteúdo e futuramente migrar para um ambiente mobile, ampliando as possibilidades de aprendizagem.

\section{Referencias}

Dias, A., Junior, G., Barrére, E., Minas, P. e de Caldas, C. (2005) "Utilizando FXRuby na construção de cenários 3D". http://www.comp.pucpcaldas.br/ al550252522/downloads/Utilizando \%20FXRuby $\% 20$ na $\% 20$ constru $\%$ E7\%E30\%20de $\% 20$ cen $\%$ E1rios $\% 203$ D.pdf, 21 de julho de 2009.

Giraffa, L E Bittencourt, J. (2003b) “A Utilização dos Role-Playing Games Digitais no Processo de Ensino-Aprendizagem”, PPGCC/PUCRS.

Giraffa, L E Bittencourt, J. (2003a) "Modelando Ambientes de Aprendizagem Virtuais utilizando Role-Playing Games”, XIV Simpósio Brasileiro de Informática na Educação, Rio de Janeiro, SBC. Valente, L. (2005) “GUFF, Um Sistema Para Desenvolvimento de Jogos”, Dissertação de Mestrado, Universidade Federal Fluminense. 